\title{
LA «MALA EDUCACIÓN» EN EL LIBRO DEL CABALLERO ET DEL ESCUDERO DE DON JUAN MANUEL
}

\author{
Carlos Heusch \\ (École normale supérieure de Lyon \\ CIHAM-UMR 5648) \\ carlos.heusch@ens-lyon.fr
}

\section{RESUMEN}

Estudio sobre lo caballeresco en el Libro del caballero et del escudero de don Juan Manuel, partiendo de la paradoja de que la parte sobre caballería no va más allá de dos folios de los veinticuatro de que consta el tratado. Don Juan Manuel retoma ideas generales del Libro sobre la orden de caballería de Ramón Llull y del título 21 de la Segunda Partida de Alfonso X. El estudio se centra luego en intentar comprender cuál sería la "mala" y la "buena" educación para el caballero según don Juan Manuel para acabar con las ambiguas relaciones entre saber y caballería a las que alude el tratado. El caballero no necesita ciencia y sin embargo de lo que más habla el tratado es de los saberes de las escuelas. ¿Cómo comprender esa nueva paradoja?

PALABRAS CLAVE: Caballería; educación; Juan Manuel; escolástica.

\section{“BAD EDUCATION" IN DON JUAN MANUEL'S LIBRO DEL CABALLERO ET DEL ESCUDERO}

\begin{abstract}
This paper focuses on chivalry in Don Juan Manuel's Libro del caballero et del escudero, starting with the paradox that the part on chivalry does not go beyond two folios of the twenty-four that the treatise consists of. Don Juan Manuel takes up general ideas from Ramón Llull's Book on the Order of Chivalry and from Title 21 of Alfonso X's Second Partida. The study then focuses on trying to understand what would be "bad" and "good" education for the knight according to Don Juan Manuel in order to put an end to the ambiguous relationship between knowledge and chivalry to which the treatise alludes. The knight does not need science and yet what the treatise talks about most is the scholastic knowledge. How can we understand this new paradox?
\end{abstract}

KEYWORDS: Chivalry; education; Juan Manuel; scholasticism. 
Don Juan Manuel se consideraba a sí mismo como un especialista del tema caballeresco o, al menos, le interesaba presentarse como tal. En el Libro de los Estados no duda en hacer una especie de accessus de sí mismo, por la boca del predicador Julio quien dice ser su amigo y haber sido su ayo, en aquella tierra lejana llamada Castilla. Al final de una especie de micro-biografía de don Johán, Julio le confiesa al Infante de dónde le viene ese saber «caballeresco», siendo él predicador (y, suponemos, fraile dominico):

Et por las grandes guerras que'l acaesçieron et por muchas cosas que vio et que pasó, despartiendo entre él et mí, sope yo por él muchas cosas que pertenesçen a la cavallería, de que yo non sabría tanto porque só clérigo, et el mio ofiçio es más de pedricar que usar de cavallería ${ }^{1}$.

La presencia de «don Johan» en el Libo de los Estados como maxima auctoritas en lo tocante a caballería va aún más lejos. En varios lugares, el mismo Julio remite a dos obras de su supuesto «amigo» en las que el Infante (pero también el lector, claro) hallará todo lo que quiera saber sobre la caballería. Estas obras son el Libro de la caballería y el Libro del caballero et del escudero. Muy poco es lo que sabemos del Libro de la caballería de don Juan Manuel puesto que no se ha conservado. No obstante, a partir de las alusiones contenidas en el Libro de los estados podemos suponer que se trataba de una versión «abreviada» ${ }^{2}$ de algunas leyes sobre la caballería del título XXI de la Segunda Partida de su tío Alfonso X $\mathrm{X}^{3}$, con elementos inspirados en Vegecio (que también conoce y cita don Juan Manuel) como la elección de los caballeros, la investidura caballeresca, la caballería como «orden», y otros relacionados con aspectos ceremoniales, simbólicos, sociales y jurídicos derivados de dichas ideas ${ }^{4}$. Basten estos pocos ejemplos. En el capítulo XC del Libro de los estados se lee lo siguiente:

\footnotetext{
${ }^{1}$ Don Juan Manuel, Libro de los estados (Madrid: Castalia, 1991), cap. Xx, 100.

${ }^{2}$ No se trataría del primer caso en Juan Manuel de "abreviación” de alguna obra alfonsí. En el mismo período, en efecto, nuestro autor había compuesto su Crónica abreviada, compendio de algunos capítulos de la Estoria de España alfonsí.

${ }^{3}$ Serían sin duda las leyes que fueran compatibles con la visión manuelina del caballero. Probablemente, don Juan Manuel no recogería en su tratado todos los aspectos políticos del título XXI que creaban de facto una sumisión de los caballeros fijosdalgo a la corona.

${ }^{4}$ Quien mejor ha estudiado la relación de intertextualidad presumible, a partir de lo apuntado por don Juan Manuel en Estados, entre las Partidas (II, 21) y el perdido Libro de la caballería es Jesús Rodríguez Velasco. Véanse: Jesús Rodríguez Velasco, El debate sobre la caballería en el siglo XV (Valladolid: Junta de Castilla y León, 1996), 18-22, 404 y passim; Order and Chivalry. Knighthood and Citizenship in Late Medieval Castile (Filadelfia: University of Pennsylvania Press, 2010) e "Invención y consecuencias de la caballería", en Josef Fleckenstein y Thomas Zotz, La caballería y el mundo caballeresco, trad. José Luis Gil Aristu (Madrid: Siglo XXI, 2006), XI-LVIII. Difiere, sobre este particular, de Taylor y Lizabe. Véase Barry Taylor, "Los capítulos perdidos del Libro del cavallero et del escudero y el Libro de la caballería", Incipit 4 (1984): 51-69; Gladys Lizabe de Savastano, "El título XXI de la segunda partida de Alfonso X, patrón medieval del tratado de caballería hispánico", en Evolución narrativa e ideologica de la literatura caballeresca, ed. María Eugenia Lacarra (Bilbao: Universidad del País Vasco, 1991), 81-102.
} 
[...] la cavallería es orden que non deve seer dada a ningún omne que fijo dalgo non sea derechamente. Et si yo vos oviese a contar todas las maneras en cómmo la cavallería fue primeramente ordenada, et en quantos peligros tan[to] del alma commo del cuerpo, se para el cavallero por mantener el estado de la cavallería, et quántas gravezas ý a, et quánto la deve reçelar ante que la tome, et cómmo deven ser los cavalleros escogidos et de cómmo deven seer fechos cavalleros, et de la onra que an después que lo son, et de las cosas que deven guardar a Dios et a la ley et a los señores et a todo el otro pueblo, só çierto que se alongaría mucho la razón. Mas si lo quisiéredes saber conplidamente fallar lo edes en los libros que fizo don Johan, aquel mio amigo: el uno, que llaman De la cavallería, et otro, que llaman el Libro del cavallero et del escudero ${ }^{5}$.

Por otro lado, en el capítulo LXVII del mismo Libro de losestados se remite, por ejemplo, al Libro de la cavallería de «don Johan» en lo tocante a la importancia de la espada para el caballero, que simboliza las cuatro virtudes que ha de tener:

Et porque los cavalleros non pueden traer sienpre todas las armas et armaduras que les cunplen, por ende los sabios antigos que ordenaron la cavallería escogieron el espada en que es todo. Et por eso ordenaron que non pudiese el cavallero reçebir orden de cavallería sinon con la espada. Et todo omne que a de bevir por cavallería deve sienpre usar de la traer consigo. Et, señor infante, si quisiéredes saber cómmo en el espada se muestran las quatro virtudes que los cavalleros deuen aver en sí, fallar lo hedes en el libro que conpuso don Johan, aquel mio, amigo, que ha nonbre el Libro de la canallería ${ }^{6}$.

Ahora bien, ese es, precisamente el tema principal de la $4^{a}$ ley del título XXI de la Segunda partida. La comparación con la más que probable fuente alfonsí es bastante significativa, por ejemplo en las últimas frases de la ley $4^{\text {a }}$ :

Esso mismo muestra el fierro de la espada que es derecho e agudo e taja egualmente de ambas las partes. E por todas estas razones establescieron los antiguos que la traxiessen siempre consigo los nobles defensores e que con ella rescibiessen honrra de caballería. E con otra arma non, porque siempre les viniesse emiente destas quatro virtudes que deven aver en sí. Ca, sin ellas, non podrían complidamente mantener el estado del defendimiento para que son puestos 7 .

Más lejos, en el capítulo LXXXVI, se vuelve a remitir al libro de «don Johan» para aludir a toda una serie de aspectos jurídicos relacionados con la caballería y su pérdida a raíz de casos delictivos que parecen también remitir a las últimas leyes del referido título $\mathrm{XXI}^{8}$.

\footnotetext{
${ }^{5}$ Don Juan Manuel, Libro de los estados, 269.

${ }^{6}$ Don Juan Manuel, Libro de los estados, 200.

7 Alfonso X, Las Siete Partidas, ed. Gregorio López (Salamanca: Andrea de Portonariis, 1555), II, XXI, 4, f. 71v.

${ }^{8}$ «Et si así non faze o en alguna cosa yerra, caye en muy grant pena, ca cosas puede fazer por que cayera en pena de traición et por [otras] cosas en pena de aleve et por otras en pena de falsidat et por otras en pena de valer menos. et por otras en pena de non seer par de fijo dalgo et por otras seer
} 
La otra obra mencionada en el Libro de los estados, el Libro del caballero et del escudero, es la que nos va a ocupar en este trabajo. Aparece citada en menos ocasiones, pero de manera mucho más precisa y, en todo caso, en un singular proceso de autoelogio indirecto por parte de don Juan Manuel quien, al final del capítulo XC, no duda en alabarse a sí mismo de nuevo a través del predicador Julio:

Et commoquiera que este libro fizo don Johan en manera de fabliella, sabet, señor Infante, que es muy buen libro e muy aprovechoso. Et todas las razones que en él se contienen son dichas por muy buenas palabras et por los más fermosos latines que yo nunca oí dezir en libro que fuese fecho en romançe; et poniendo declaradamente e conplida la razón que quiere decir, pónela en las menos palabras que pueden seer9.

Juan Manuel quiere, por lo tanto, dejar constancia en el Libro de losestados de que su obra anterior no es solo un modelo de tratado caballeresco sino también un modelo de perfección formal. Pero, ¿hasta qué punto es eso cierto? ¿Acaso es el Libro del caballero et del escudero ese parangón de la «buena educación» del caballero formulada, además, de manera perfecta - con «fermosos latines»- y concisa, «en las menos palabras», ateniéndose por lo tanto a lo que sería la «razón» del libro, es decir el aprendizaje de la caballería por parte de un escudero? ¿Qué educación ofrece el Libro del caballero et del escudero a un público de aspirantes a caballeros en la Castilla de Alfonso XI?

\section{DE LLULL A DON JUAN MANUEL O DE LA FÁBULA A LA «FABLIELLA»}

Como ya lo he sugerido, Juan Manuel disponía de algunos modelos muy próximos a él para componer un libro de educación caballeresca. Hace referencia a Vegecio al principio del Libro del caballero et del escudero, en el capítulo XIX en el que el caballero anciano ha de contestar precisamente a la pregunta «qué cosa es caballería»: «si vos quisiéredes saber todo esto que me preguntastes de la cavallería conplidamente, leed un libro que fizo un sabio que dizen Vejeçio et ý lo fallaredes todo $»^{10}$. Pero, qué duda cabe de que también tiene presente el título XXI de la Segunda Partida como podemos suponer, con algunos estudiosos ya citados ${ }^{11}$, que lo tenía presente en su perdido Libro de la caballería. Ahora bien, el punto de partida de la obra que nos ocupa no se halla en ninguno de estos textos sino en otro al que alude don Juan Manuel en el prólogo interno de la obra:

enfamado. Et, sennor infante, porque se alongara mucho la razón si vos oviese a dezir la diferencia et departimiento que a entre cada [una] destas cosas, et por quales cosas puede el omne caer en cada una destas cosas o qué es la pena que meresçe por cada una dellas, por non alongar mucho este libro non vos las digo aquí, mas si lo quisierdes saber, fallarlo hedes en el libro que don Johan, aquel mio amigo, fizo, que llaman De la cavallerías (Don Juan Manuel, Libro de los estados, 257).

${ }^{9}$ Don Juan Manuel, Libro de los estados, 269-270.

${ }^{10}$ Libro del caballero et del escudero (BNM, ms. 6376, f. 3v). Véase también El libro del caballero et del escudero, en Obras completas, ed. José Manuel Blecua, 2 vols. (Madrid: Gredos, 1981), I, 46.

${ }^{11}$ Véanse los citados trabajos de Rodríguez Velasco, Taylor y Lizabe. 
Yo don Johan, fijo del Infante don Manuel, fiz este libro en que puse algunas cosas que fallé en un libro, et si el comienço dél es verdadero o non, yo non lo sé. Mas que me paresçió que las razones que en él se contenían eran muy buenas tove que era mejor de las scrivir que de las dexar caer en olvido. Et otrosí puse ý algunas otras razones que fallé scriptas et otras algunas que yo puse que perteneçían para seer ý puestas $^{12}$.

Ese misterioso libro deja de serlo cuando leemos lo que sigue: «Dize en el comienço de aquel libro que en una tierra avía un rey muy bueno et muy onrado[...] $\rangle^{13}$. Este «comienzo de libro» no es sino el del Llibre qui és de l'orde de cavalleria de Ramón Llull, escrito medio siglo antes y que sin duda conocería don Juan Manuel, como conocía otras obras lulianas, merced a sus contactos familiares y personales con la corona de Aragón y aún con el reino de Mallorca, pues Jaime II de Mallorca -a quien van dirigidas bastantes obras de Llull- fue su primer suegro, tras su matrimonio con la hija de aquel, Isabel de Mallorca. Y es bien cierto que la obra de Ramón Llull podía ser vista como un modelo de tratado sobre la caballería, lo cual era ya razón suficiente para que pudiera interesar al prócer castellano si alguien le habló de ella, tal vez en Perpiñán en 1299 cuando se desposó con la infanta mallorquina. El marco ficcional del libro de Llull viene a ser el mismo que el del de don Juan Manuel: el encuentro entre un anciano caballero, retirado del mundo en una ermita y un joven escudero que se ha quedado dormido encima de su caballo yendo a las cortes de un rey, con la intención de ser armado caballero. Tras un diálogo relativamente breve (toda esa historia es, de hecho, el «prólogo» del libro de Llull), el anciano caballero le regala al joven escudero el libro que suele leer y que contiene cuanto hay que saber para ser un buen caballero. El joven escudero se lo agradece sobremanera y el ermitaño le invita a volver cuando ya sea armado caballero $^{14}$ (cosa que el personaje luliano no hará, contrariamente al de don Juan Manuel). En los capítulos siguientes, el lector puede ver el contenido del libro regalado al que se refiere el «relato marco» pues ambos libros, el de la historia y el que tiene el lector entre sus manos, acaban fundiéndose, aunque el destinatario sea el escudero, un pequeño juego muy del gusto de Llull.

El tratado de Llull guarda algunas analogías con el título XXI de la Segunda partida pero que, desde mi punto de vista, podrían deberse más a coincidencia de fuentes (como Vegecio o San Bernardo) ya que resulta poco probable un conocimiento por parte de Llull de la magna obra jurídica del Rey Sabio. En él vamos a encontrar un concepto trascendente de la caballería considerada como la mayor dignidad entre los legos. Como Alfonso X, Llull considera que solo los nobles de antiguo linaje deben ser caballeros, algo que don Juan Manuel afirmará también. Sin duda la gran diferencia entre la caballería luliana y la alfonsí estriba en el cariz

${ }^{12}$ Libro del caballero et del escudero (BNM, ms. 6376, f. 2v). Véase también ed. Blecua, 41.

${ }^{13}$ Ibídem.

${ }^{14} \ll \mathrm{E}$ con serets adobat a novell cavaller, retornats per aquest loch, e digatsme quals son aquells qui serán fets novells cavallers...». Ramon Llull, Llibre qui és de l'orde de cavalleria, en Obres de Ramon Llull, ed. Mateo Obrador y Bennassar, 13 vols (Palma de Mallorca: Miquel Font, 1986), I, 207. 
marcadamente espiritualista que tiene, en la pluma del teólogo mallorquín. Este se inspira en el modelo de la caballería de Dios de San Bernardo y considera que, si bien los caballeros están para defender la tierra y sus señores, su cometido principal es el de «mantener y defender la santa fe católica» ${ }^{15} \mathrm{y}$, por consiguiente, deben luchar contra los «infieles que cada día obran a favor de la destrucción de la Santa Iglesia» ${ }^{16}$.

La influencia de Llull en la concepción juanmanuelina de la caballería aparece con claridad en la dimensión espiritual de la caballería. En el escritor castellano encontraremos esa defensa de una caballería cristiana que depende más de Dios que del brazo terrenal, un punto que don Juan Manuel desarrollará incluso más que el mallorquín como reacción a la actualización del concepto alfonsí de la caballería, en tiempos de Alfonso XI. En don Juan Manuel la idea de caballería espiritual es uno de los principales instrumentos para llevar a cabo una tenaz defensa de los intereses señoriales, con respecto a la extensión del poder regio, algo que no se plantea en el tratado luliano.

En Llull, sin embargo, tal vez aparezca con mayor nitidez que en los otros textos la idea de una caballería que no solo es espiritual, sino que además está sometida a un riguroso código ético y moral, más allá de cuestiones como la honra o la vergüenza: el caballero luliano debe seguir una regla estricta con implicaciones concretas en muchos aspectos de la vida. Es la plasmación de un auténtico ideal caballeresco cortés tal y como se había diseñado, al menos teóricamente, en el reino de Francia y en la Inglaterra de los Plantagenêt, un concepto que empezará tan solo a vislumbrarse en Castilla con el Ordenamiento de la banda, algo posterior al libro de don Juan Manuel. Según este estricto ideal, el caballero no tiene más que deberes: defender la justicia y sobre todo a los inermes, tales como viudas, huérfanos y hombres sin medios de defensa, y en él solo deben brillar la bondad y todas las virtudes. Ello lo conduce asimismo a obrar por la paz: el caballero ideal de Ramón Llull no quiere la guerra, sino que ha de «pacificar a los hombres por la fuerza de las armas» ${ }^{17}$. De ahí que sea un oficio no solo peligroso sino tan duro que solo la «vergüenza» (la «vergonya» ${ }^{18}$ ) puede ser una fuerza suficiente para que el caballero no se eche atrás. Es la verecundia de la que habla Vegecio ${ }^{19}$, de tan hondo calado en Alfonso X y en don Juan Manuel, como veremos a continuación, quien hará de ella, en el ejemplo L del Conde Lucanor, lo más importante que debe poseer el hombre ${ }^{20}$.

\footnotetext{
15 «Offici de cavaller es mantener e deffendre la sancta fe catholica» (ibídem, 212).

16 «Los infels qui cada die punyen en lo destruiment de la Sancta Sgleya» (ibídem).

17 «Es offici de cavaller pacificar los homens per forsa darmes» (ibídem, 222).

18 «Car cavaller deu més dubtar blasme de gents que mort: e vergonya deu donar major passio a son coratge que fam, ni set, ni calt, ni fret, ni altra passio ni treball a son cors. E per assò tots aquests perills deuen esser mostrats e denunciats al scuder, ans que sie adobat cavaller» (ibídem, 226).

19 «Honestas enim idoneum militem reddit, uerecundia, dum prohibet fugere, facit esse uictorem» (Flavi Vegeti, Epitoma rei militaris, I, 7, https://www.thelatinlibrary.com/vegetius1.html [fecha de consulta: 31/1/2021]).

${ }^{20}$ Vid. Don Juan Manuel, Libro del conde Lucanor, «Exemplo L, De lo que contesció a Saladín con una dueña, muger de un su vasallo»: «Estonce le dixo Saladín quel plazía desto que ella le dizía et díxol que la repuesta de la pregunta que ella fiziera que era esta: que ella le preguntara cuál era la mejor cosa que omne podía aver en sí, et que era madre et cabeça de todas las bondades: quel respondía que la
} 
Ramón Llull describe pues un concepto idealizado de la caballería courtoise que será el que fascine al Cuatrocientos castellano en obras como el Victorial de Gutierre Díez de Games o en algunos textos de Diego de Valera, pero que, en la primera mitad del siglo XIV, no coincidía con la realidad militar y social de los llamados «caballeros». No en vano las apariciones de estos en los textos de la época suelen ser bastante negativas (desde el Libro de buen amor hasta el Rimado de palacio): soldados de mala vida, holgazanes, tahúres y mercenarios codiciosos ${ }^{21}$. La educación del caballero courtois en la Castilla del siglo XIV estaba tan solo empezando, en obras, por ejemplo, como el referido Ordenamiento de la banda. Recordemos, sin embargo, que dicho ordenamiento no se dirigía a todos los caballeros sino tan solo a una reducida elite sociopolítica en el entourage del monarca.

De ahí que podamos pensar que para don Juan Manuel un tratado como el de Ramón Llull hubiera podido ser una fuente perfecta ya que en él aparecía todo lo necesario para "educar" al futuro caballero. Sin embargo, del tratado de Llull se queda ante todo con el marco ficcional, la historia de aquel rey tan bueno -una figura que don Juan Manuel desarrolla mucho más que Llull, sin duda para poder llevar a cabo un retrato invertido del por él tan detestado Alfonso XI, modelo, por el contrario, de mal rey, de esos reyes, como se dirá luego en el libro, que son como los vientos fuertes que levantan las tempestades en la mar, provocando el hundimiento de las naves que por ella bogan, entiéndase los vasallos-. Se queda también con los personajes principales: el genial hallazgo luliano del caballero anciano, convertido en ermitaño, posiblemente a partir de la figura legendaria del caballero inglés Guy de Warwick, y el joven y talentoso escudero llamado a ser uno de esos «mejores caballeros del mundo» que tanta impronta literaria iban a tener. Y todo ello, el marco narrativo (los personajes y la historia) configura sin duda lo que don Juan Manuel llama «fabliella». Se queda asimismo con una serie de ideas generales sobre la caballería que, como veremos, no va a desarrollar. En definitiva, disponía don Juan Manuel de todo lo necesario para dar a los «defensores» que lo rodeaban, a menudo presentados como zafios por los textos, acaso esos mismos que le echaban en cara que escribiera libros ${ }^{22}$, la buena educación caballeresca que ellos necesitaban. Pero don Juan Manuel decidió hacer otra cosa, no le interesaba reproducir el modelo sino trabajarlo, rescribirlo para orientarlo hacia otros derroteros que no eran la estricta buena educación de la caballería courtoise.

mejor cosa que omne podía aver en sí et que es madre et cabeça de todas las bondades que esta es la vergüença» (ed. Guillermo Serés [Barcelona: Crítica, 2001], 208-209, 216).

${ }^{21}$ VéaseJuan Ruiz, Arcipreste de Hita, Libro de buen amor, ed. Jacques Joset (Madrid: Taurus, 1990), copla 1253; Pero López de Ayala, Rimado de Palacio, ed. Hugo Bizarri (Madrid: Real Academia Española-Galaxia Gutenberg, 2012), coplas 260, 338, 487, 506 passim.

22Pienso en todos aquellos que, según don Juan Manuel, «profazaban» de él porque «hacía libros». Véase Libro infinido, «Et commoquier que yo sé que algunos profaçan de mí porque fago libros, dígovos que por eso non lo dexaré [...]» (Don Juan Manuel, Libro infinido, ed. Carlos Mota [Madrid: Cátedra, 2003], 176). 


\section{LO CABALLERESCO EN EL LIBRO DEL CABALLERO ET DEL ESCUDERO}

Es lógico suponer que antes de que se perdieran los cuatro folios, entre el folio $2 \mathrm{v}$ y el folio $3 \mathrm{r}$, del único testimonio de la obra, aparecía en el libro la lista de las preguntas que le quiere hacer el joven escudero al viejo caballero y que, sin duda, funcionaría como índice inicial de capítulos, como ocurre en otras obras de don Juan Manuel. Afortunadamente, cuando el ya caballero novel regresa, unos años después, el anciano vuelve a enunciar -aunque en desorden- la lista de preguntas del principio con lo cual podemos, de hecho, identificar con cierta precisión los temas tratados en el libro. La lista es larga y no la vamos a citar aquí. Digamos, sin embargo, que de los veintiséis temas tratados que versan sobre las más diversas materias (cielos, piedras, aves, peces, etc.), tan solo dos hablan de la caballería: «¿qué cosa es caballería?», por un lado y «¿cuál es el mayor y más honrado estado entre los legos?» El resultado de tal reducción temática es que, de los veinticuatro folios del tratado, solo dos tienen como tema explícito la caballería y se encuentran al principio de la obra. Ahora bien, como vamos a ver, en alguna que otra digresión, en los capítulos sucesivos dirigidos no ya al escudero inexperto sino al ducho caballero, se vuelve a tocar el tema de la caballería, pero en medio de una exposición sobre otra cosa. ¿Qué ha pasado con el tratado de educación caballeresca?

Antes de contestar a esa pregunta veamos rápidamente qué dice el caballero anciano al escudero en esos dos capítulos iniciales sobre la caballería. En los capítulos XVIII y XIX, dedicados a la caballería, don Juan Manuel retoma muy someramente ideas generales que se hallan en las fuentes luliana y alfonsí. Dice que la caballería es el mayor y más honrado estado entre los legos, algo que afirma también Llull. Añade, sin embargo, don Juan Manuel un detalle económico que, creo, no está en el mallorquín cuando explica por qué es el mayor estado. Ciertamente porque los caballeros son los que han de defender a todos los otros estados y ahí entronca don Juan Manuel con la asimilación que hacen las Partidas de los caballeros con los «defensores». Pero la consecuencia es que, a cambio de dicha defensa, los otros estados deben «mantenen» a los caballeros: «Ca los cavalleros son para defender et defienden a los otros, et los otros deven pechar et mantener a ellos» ${ }^{23}$. Así pues, surge la idea de una «financiación» de la caballería por parte de los pecheros es decir los «labradores», como los llama en el capítulo anterior en el que aparece la división tripartita estamental que tanto le gusta a nuestro autor. De ahí que, desde el punto de vista socioeconómico la caballería pueda aparecer como una milicia al servicio de la corona, mientras que Ramón Llull asocia plenamente la caballería a la nobleza terrateniente que vive, en castillos, de las rentas de sus heredades.

La segunda idea importante es la asimilación de la caballería a un sacramento, «semeja mucho a los sacramentos» ${ }^{24}$. Se trata de retomar indirectamente la dimensión

${ }^{23}$ Don Juan Manuel, Libro del caballero et del escudero (BNM, ms. 6376, f. 3r). Véase también ed. cit. de Blecua, 44.

${ }^{24}$ Ibídem, f. 3v y ed. Blecua, 45. 
espiritual de la caballería presente en San Bernardo o en Ramón Llull pero indicando su modus operandi. Por ser algo trascendente, por ser una orden, no se puede obtener si no se da, como el bautismo, la bendición, etc. De ahí que concluya el capítulo con una somerísima descripción del proceso sacramental de la investidura caballeresca: para que la caballería sea «complida» se requiere el que la da; el que la recibe y la espada que simbólicamente plasma la transmisión de la orden con su efecto ontológico. Este es un punto fundamental que desarrollan ampliamente las primeras leyes del título XXI sobre la caballería de la SegundaPartida y puede resultar sorprendente que don Juan Manuel le dedique tan pocas líneas.

El capítulo XX debiera desarrollar plenamente la parte «tratado de caballería» de la obra puesto que ha de contestar a la pregunta «qué cosa es la caballería». El escudero y el lector no pueden por menos de quedar atónitos al oír la reticencia del caballero anciano a la hora de hablar de caballería:

Avié mester muchas palabras para lo mostrar todo conplidamente, et sería muy grant departimiento, non vos quiero dezir en ella si non pocas palabras; pero si vos quisiéredes saber todo esto que me preguntastes de la cavallería conplidamente, leed un libro que fizo un sabio que dizen Vejeçio et ý lo fallaredes todo ${ }^{25}$.

No puede haber renuncia más explícita. El tratado sobre la caballería (y no olvidemos que así es como Julio presenta el libro en el Libro de los estados) se va a convertir en unas "pocas palabras». Buen samaritano, el caballero anciano le da, al menos, al escudero una referencia bibliográfica importante, el De re militari de Vegecio obra que, en aquel entonces, solo podía ser leída en latín en la península Ibérica. En definitiva, no parece este caballero anciano muy dispuesto a educar al futuro caballero.

Las pocas palabras que dice el caballero anciano giran en torno a tres puntos: la caballería está supeditada a la gracia de Dios y para conservarla y llevarla adelante son necesarios el «seso» y la «vergüença», dos nociones fundamentales que, como ya he dicho, don Juan Manuel encuentra en Vegecio y en Llull quien insiste sobremanera en la noción de seny, el sentido común, el buen sentido, es decir el «seso» de don Juan Manuel, un aspecto que prácticamente no aparece en el título de las Partidas. Sí, en cambio, aparece la vergüenza que tanto Alfonso como don Juan Manuel glosan y desarrollan mucho más que el mallorquín que se contenta con retomar el concepto vegeciano de verecundia. Tanto para Alfonso como para don Juan Manuel, la vergüenza se convierte en la piedra de toque de la caballería, pero con un uso distinto. En las Partidas, la vergüenza tiene una dimensión sociopolítica mientras que en don Juan Manuel tiene una dimensión moral. Para don Juan Manuel, en efecto, la vergüenza es una fuerza moral inspirada por Dios que hace que no queramos ofender a Dios con una actitud reprensible y, en este sentido, no está muy alejada del concepto teológico de contrición ${ }^{26}$. Para Alfonso, en cambio, no es un

25 Ibídem, f. 3v y ed. Blecua, 46.

${ }^{26}$ Son varios en don Juan Manuel, los ejes semánticos de la noción de «vergüenza». Al caballeresco de raigambre vegeciana hay que añadir uno más moral que acaso encuentra don Juan Manuel en la literatura sapiencial, como lo sugiere Cacho Blecua. Véase Juan Manuel Cacho Blecua, "Vergüenza, 
valor moral y por lo tanto universal, sino que es social: solo los nobles tienen vergüenza $\mathrm{y}$, por consiguiente, solo los nobles, los fijosdalgo, deben ser caballeros. Don Juan Manuel afirmará también la necesaria hidalguía del caballero, pero, curiosamente, no la justifica por la vergüenza sino por la honra social inherente al grupo nobiliario.

En el capítulo XXXV, dedicado a «los cielos», el caballero anciano se permite una digresión para volver al tema de la caballería comentando la diferencia entre el valor y el miedo, concretamente en el caballero. $\mathrm{Y}$ eso viene a ser todo, amén de algunos comentarios o pequeñas digresiones en las que se alude muy de pasada al caballero y lo que ha de hacer o no. Volveremos sobre ello, pero quedémonos por de pronto con esta idea de una sorprendente «mala educación» caballeresca de este libro por la parte tan ínfima que le dedica el tratado al tema. Tenemos que fijarnos entonces en los demás aspectos para intentar ver si en los otros ámbitos del libro está la buena educación o, al contrario, una educación aún peor para el caballero.

\section{MANCEBÍA Y MALA EDUCACIÓN}

Ya conocemos la metis ulísea de don Juan Manuel, una virtud que, en el fondo, le permitió morir de muerte natural y no asesinado por alguno de sus enemigos, empezando por el rey de Castilla. Pero ello significa que sin duda la complejidad del Libro del caballero et del escudero que observamos en lo tocante a la educación caballeresca es algo deliberado. Ciertamente, es el caballero anciano ( $\mathrm{y}$, en primera instancia, don Juan Manuel) quien decide que los capítulos sobre la caballería no sean más extensos. Ahora bien, siguiendo el mismo razonamiento, es el escudero mancebo quien ha decidido que la mayor parte de las preguntas que le hace al viejo caballero tengan tan poca relación con el tema de la caballería stricto sensu, puesto que él es quien las ha formulado y el anciano caballero, por cortesía (entre otras cosas), se siente obligado a contestar, aunque a menudo con mal talante. El problema del contenido de este libro reside precisamente ahí, en esa constatación a la vez evidente y traída por los cabellos, de que por ser «en manera de preguntas et respuestas» son las preguntas las que determinan el contenido del libro. Esa es la regla del juego. Y prácticamente todas las preguntas del joven escudero son inadecuadas para instruirlo en el oficio de la caballería. Lo que sí parece claro es que era a don Juan Manuel a quien no le apetecía demasiado seguir hablando de caballería, tras haber compuesto (quizás) con anterioridad su desaparecido Libro de la caballería y que sin duda le apetecía más tratar otros temas, precisamente aquellos que plantea el joven escudero, esos temas que no dejarán de fascinarle a lo largo de su obra escrita y que son tan ajenos a su «oficio» de defensor.

El caso es que, salvo contadas excepciones, las preguntas que plantea el joven escudero no son, como digo, las de un aprendiz de caballero sino las de un estudiante en las escuelas, las de un futuro clérigo o letrado, con todo el afán incontrolable de

sabiduría y pecado en la literatura medieval castellana (del Bonium a don Juan Manuel)", Príncipe de Viana. Anejo 18 (2000): 75-102. 
saber de la «alegre mancebía», como diría Rojas. En efecto, esas preguntas tienen que ver con las «ciencias» que se estudian en las escuelas y no con el oficio de la caballería. ¿Por qué las formula entonces? Lo diremos en la conclusión. Quedémonos, por el momento, con la idea de que, prácticamente al principio de cada respuesta, el caballero anciano se ve obligado a hacer una especie de captatio benevolentiae para justificar lo somero de sus respuestas pues el tema atañe a un campo muy alejado de su antiguo oficio que él no ha estudiado puesto que, en el fondo, como nos lo dice él mismo, no sabe nada de la ciencia: «yo nunca leý nin aprendí ninguna sçiençia» ${ }^{27}$.

Pero el caballero anciano va aún más allá. No se trata tan solo de hacer una captatio benevolentiae dirigida tanto al destinatario interno como al externo -el lectorpara que nadie le reproche lo poco profesional de sus respuestas. En un momento dado afirma lo inapropiado de estos saberes en aquellos que no son «profesionales» de dichas ciencias, es decir aquellos que no forman parte del estado de los oratores. Los legos, dice, no han de conocer ciertas cosas que tienen que ver con la teología o la escatología (estamos en un capítulo -el XXXIV- sobre el infierno): «los legos non son tenidos a saber dellas, si non creer simplemente lo que sancta Eglesia manda» ${ }^{28}$. Esto se comprueba aún más en los caballeros puesto que ya tienen otras misiones muy importantes como para ponerse a curiosear por esos derroteros resbaladizos:

[...] mayormientre los cavalleros que an tanto de fazer en mantener el estado en que están que es de muy grant periglo et de muy grant trabajo, que non han tienpo nin letradura para lo poder saber conplidamente ${ }^{29}$.

Así pues, sin querer hablar más de caballería, el astuto don Juan Manuel va destilando informaciones esenciales como la de que los caballeros no deben pretender saber lo que se sale de su campo profesional y de su praxis. Sería sin duda una mala educación para ellos decir más de la cuenta en estos ámbitos que no son de su oficio. ¿Quién habla aquí? ¿El viejo caballero o don Juan Manuel? No es fácil decirlo porque, por un lado, la idea no sorprende, es corriente hasta bien entrado el siglo XV, como lo demuestra la carta de Alfonso de Cartagena al conde de Haro, brillantemente estudiada por Jeremy Lawrance ${ }^{30}$, y tiene que ver con la división estamental de los saberes, tan apegada a la episteme escolástica, frente a ciertas aperturas humanísticas. Por otro lado, a pesar de las precauciones oratorias, Juan Manuel, a todas luces, se aprovecha de todas esas preguntas, presuntamente impertinentes en los labios de un escudero, para hablar sin duda de lo que más le interesa a él que son, precisamente, como ya se ha dicho, todas esas ciencias ajenas a su oficio de bellator. Pero lo que sigue en el capítulo que nos ocupa vuelve esta interpretación aún más compleja. El caballero anciano sabe que la definición de la caballería implica que los caballeros sean personas sesudas y eso los hace especialmente vulnerables ante la tentación de saber que, siguiendo el esquema

\footnotetext{
${ }^{27}$ Ibídem, f. 7r y ed. Blecua, 59.

${ }^{28} \mathrm{Ibídem,} \mathrm{f.} \mathrm{8v} \mathrm{y} \mathrm{ed.} \mathrm{Blecua,} 65$.

${ }^{29}$ Ibídem, ff. 8v-9r y ed. Blecua, 65.

${ }^{30}$ Jeremy Lawrance, "La autoridad de la letra: un aspecto de la lucha entre humanistas y escolásticos en la Castilla del siglo XV”, Atalaya 2 (1991): 85-107.
} 
bíblico, es una tentación diabólica. Cuanto más inteligente es el caballero, más debe alejarse del «árbol de la ciencia» para no ser tentado por el Maligno:

Et por ende, quando [el diablo] falla que alguno es muy sotil et muy entendudo trabájasse de'l fazer pensar en las cosas que son de Dios et de la fe marabillosas et muy ascondidas por le fazer caer en alguna dubda. Ca la sotileza les faze pensar muchas cosas et por la mengua de la letradura non pueden saber la verdad conplidamente cómmo es. Et así podrié caer en grandes yerros et en grandes dubdas. Et por ende yo que bisqué mucho en estado de cavallero et non aprendí otra sçiençia sienpre fiz quanto pudi por partir el coraçón de non cuydar estas $\operatorname{cosas}^{31}$.

En este ámbito, la «buena educación» se convierte en total «ausencia» de educación, apartarse totalmente de dichas interrogaciones; a la inversa, dar información a los mancebos, en este coto vedado de los «theóricos», sería una nefanda educación en el caballero pues podría hacerle perder el alma. A fuer de prudente caballero, el caballero anciano confiesa, por lo tanto, haberse mantenido siempre al margen de esas cuestiones. Y, sin embargo, es él quien contesta al joven escudero... En cualquier caso, lo que sí está claro es que ciertas ciencias que son «de» y «para» los oratores, sí «embotan el hierro de la lanza» y no solo «hacen floja la espada en la mano del caballero», sino que pueden condenarlo a las penas del infierno, que de eso se trata en este capítulo. Don Juan Manuel (si podemos hacerle responsable de las afirmaciones del viejo caballero) parece estar abogando por lo que podríamos llamar una «estatificación» típicamente escolástica de los saberes. Los saberes han de quedar enmarcados en los estados. Dicha idea cerrada del saber en una «sociedad estática», en expresión de Maravall ${ }^{32}$, parece evidente aquí. En don Juan Manuel todo ha de hacerse en función del estado de cada uno y con el saber y la educación pasa tanto de lo mismo. No conviene que el caballero deba aprender ciertas cosas que no son de su incumbencia porque no son propias de las actividades de su estado.

Todo eso plantea el problema de saber si la caballería necesita una ciencia específica o no. En el Llibre de l'orde de cavalleria la respuesta de Ramón Llull es ambigua. Empieza afirmando que la caballería no se aprende en las escuelas o, mejor dicho, que la escuela de la caballería no ha de ser entre cuatro paredes y con los codos recostados sobre un viejo pupitre sino cabalgando al aire libre y sirviendo a un señor que sea aquel maestro que le enseñe el oficio de caballero, como el carpintero o el zapatero enseña el oficio a su aprendiz ${ }^{33}$. Y, sin embargo, en el párrafo siguiente, Ramón Llull formula un deseo en condicional: «seria conveniente, dice, que se hiciera una escuela de la orden de caballería y que fuera una ciencia escrita en libros y que

\footnotetext{
${ }^{31}$ Don Juan Manuel, Libro del caballero et del escudero, f. 9r y ed. Blecua, 65.

32José Antonio Maravall, "La idea del saber en una sociedad estática", Cuadernos Hispanoamericanos 197-198 (1966): 324-350 y 533-557.

33 VéaseRamon Llull, Llibre de l'orde de cavalleria, I, 11-12, 210-211.
} 
fuera arte enseñada, así como lo son las otras ciencias» ${ }^{34}$. El Libro del caballero et del escudero parece decirnos lo contrario: don Juan Manuel se queda tan solo con la primera idea de Llull, la de una caballería como «mester», un oficio como el de carpintero o zapatero que no ha de enseñarse en las escuelas, sino que ha de practicarse, ha de ejercitarse. Ahí es donde reside la buena educación del caballero y no en los libros. Estamos hablando de la primera mitad del siglo XIV, pero, como ya sabemos, este debate no solo se mantendrá en la centuria siguiente, sino que se agudizará35.

En varias ocasiones, el caballero anciano insiste en la idea de que para el caballero lo mejor es la experiencia, mucho más que la ciencia, criarse no en las escuelas sino en las casas de los señores:

Para los legos non ha tan buena escuela en el mundo cuemo criarse omne et bevir en casa de los señores, ca ý se ayuntan muchos buenos et muchos sabios et el que ha sabor de aprender cosas por que vala más en ningún lugar non las puede mejor aprender ${ }^{36}$.

Subrayo la expresión «aprender cosas por que vala más» pues es, en mi entender, la clave de todo. Solo hay que saber aquello que le mantiene a uno en su estado y le hace prosperar en él, «valer más». El mismo caballero anciano, en más de una ocasión, basa su auctoritas no en lo que ha estudiado (repitamos que dice sistemáticamente que no ha leído tal o cual ciencia) sino en lo que ha experimentado, en lo que ha vivido. La vida se convierte en la única escuela oportuna de la caballería. Son tantos los ejemplos de esta idea en el libro que resultaría farragoso citarlos todos.

El corolario de lo que acabo de apuntar es que lo que se valora en el caballero, entre las líneas de todos esos capítulos que paradójicamente hablan de lo que no debe saber el caballero, no son los conocimientos, no es el saber, sino el entendimiento, el ingenium. El mismo caballero novel insiste en el hecho de que lo que más singulariza a su maestro es, precisamente, el entendimiento que Dios le ha dado:

Ca quanto menos leýstes et sabedes más que los otros que mucho an studiado, por vuestro entendimiento tanto es çierto que vos fizo Dios mayor gracia en vos dar el entendimiento por que sopiésedes lo que sabedes ${ }^{37}$.

Repetidas veces, el caballero anciano afirma el carácter capital del puro entendimiento en el caballero. $\mathrm{Y}$ el entendimiento no requiere conocimientos librescos. Saber sin aprender, saber por puro entendimiento, ese es el ideal del caballero que se sabe constreñir dentro de los límites culturales de su oficio y estado, un ideal que perfila claramente los límites de una educación caballeresca. Y es que,

\footnotetext{
34 «Hoc encara seria covinent cosa que hom del orde de cavalleria faés scola, e que fos sciencia scrita en libres, e que fos art mostrada, axi com son mostrades les altres sciencies» (ibídem, I, 13, 211).

${ }^{35}$ Véase Jesús R. Velasco, El debate sobre la caballería en el siglo XV (Valladolid: Junta de Castilla y León, 1996).

${ }^{36}$ Don Juan Manuel, Libro del caballero et del escudero, f. 7r-v y ed. Blecua, 59.

${ }^{37}$ Ibídem, f. $7 \mathrm{r}$ y ed. Blecua, 58.
} 
como lo dirá también el Julio del Libro de los estados, los tiempos apresurados de las guerras no son para vagar volviendo las hojas de los libros ${ }^{38}$.

Como hemos visto, el Libro del caballero et del escudero es un buen ejemplo de esa especie de duplicidad que caracteriza a don Juan Manuel que, en el fondo, fue un ser escindido, desgarrado entre su calidad de bellator y su fruición por la cultura escrita más propia de un orator, sobre todo en el contexto sociocultural del siglo XIV. No olvidemos que don Juan Manuel fue uno de los primeros nobles con «letradura», capaz de codearse intelectualmente con destacados oratores y capaz de sugerir, aunque fuera entre veras y burlas, que le tradujeran uno de sus libros al latín. No es de extrañar que algunos «profazaran de él» porque «fazía libros», como lo confiesa -ya se ha dicho- en una de sus últimas obras, el Libro infinido.

Resulta tanto más asombrosa la referida sugerencia de una traducción latina cuanto que la obra de la que se trata es, precisamente, el Libro del caballero et del escudero. Latinizar los hermosos latines de don Juan Manuel era aceptar que el contenido de la obra no tenía que ver con la formación caballeresca dirigida a los legos sino con otra formación mucho más avezada a la «prudente lengua de los theóricos» como llamará, hacia 1450, Fernando de la Torre al latín ${ }^{39}$. El examen entre líneas y sin prejuicios del Libro del caballero et del escudero echa de ver que la obra no sigue los parámetros didácticos del ámbito caballeresco sino una situación que remeda la transmisión de saber en el marco de las escuelas, de esas escuelas que, precisamente, no son para el caballero. Parece haber ahí una contradicción.

Si hacemos abstracción del título y de quién es quién nos damos cuenta de que lo que este juego de preguntas y respuestas remeda es más bien una obra como el Lucidario, realizada en un contexto cultural que don Juan Manuel conocía bien puesto que fue donde se formó: la escuela catedralicia de Toledo de donde saldría la mayor parte de las obras supervisadas por el rey Sancho IV. Como por casualidad, en este contexto cultural que produce el Lucidario vamos a hallar la problemática que desarrolla don Juan Manuel, mucho más en este libro que en otros, de la necesidad de controlar y aún limitar la difusión de los saberes. Ciertamente, empieza el tratado de don Juan Manuel con una trillada defensa del saber como «la mejor cosa del mundo» ${ }^{40}$, pero ¿de qué saber se trata? ¿Qué debemos hacer con ese saber? En el Prólogo del Lucidario, el rey Sancho IV ya había contestado a esas preguntas. Ordena el libro que está prologando «porque los entendimientos de los omnes se quieren

\footnotetext{
38 «Ca todo quanto vos yo digo, et aun lo que se non dezir puede, el buen entendimiento et grant esfuerço le mostrará cómmo lo deve fazer, et así lo faga, et con la merçed de Dios et con la su ayuda acabará lo quel cunpliere. Mas por mucho que escrivamos, si él non oviere buen entendimiento de suyo, todo le prestará poco. Ca bien entendedes, señor infante, que en los tienpos apresuarados de las guerras et de las lides, non puede aver vagar entonçe de bolver las fojas de los libros para estudiar con ellos» (Don Juan Manuel, Libro de los estados, 220-221).

${ }^{39}$ Fernando de la Torre, Libro de las veinte cartas e questiones: "De un gradesçimiento e salva de mosén Fernando a una señora", en María Jesús Díez Garretas, ed., La obra literaria de Fernando de la Torre (Valladolid: Universidad, 1983), 188.

${ }^{40}$ «Dizen todos los sabios que la mejor cosa del mundo es el saber [...]». Don Juan Manuel, Libro del caballero et del escudero, f. $2 \mathrm{v}$ y ed. Blecua, 41.
} 
estender a saber e a demandar las cosas más que les es dado e non les abonda saber» ${ }^{41}$. Y de esa voluntad de saber vienen las herejías y todos los errores de los que habla, en términos muy parecidos, don Juan Manuel en el referido capítulo sobre el infierno. De nuevo, el temible «árbol de la ciencia». Hay que controlar por lo tanto la educación de todos esos mancebos que quieren saber más de lo que deben; darles lo justo para calmarles momentáneamente la sed, pero no para saciarles.

Desde este punto de vista, el Libro del caballero et del escudero y el Lucidario (que don Juan Manuel conocía sin duda) tienen un esquema totalmente análogo y ello tanto más cuanto que el libro de don Juan Manuel, en realidad, pone en escena a un maestro y a un discípulo que quiere saber lo mismo que el joven del Lucidario: teología y «naturas» y sus preguntas giran en torno a esas dos ciencias que son las que cuentan, como lo afirma el rey Sancho en el Prólogo. Así como el maestro del Lucidario limita la transmisión del saber por la existencia de saberes vedados, el caballero anciano procederá del mismo modo, pero por la existencia de estados cultural e intelectualmente estancos. En realidad, el libro de don Juan Manuel no es sino el «Lucidario de los caballeros», compartiendo con los letrados toledanos de Sancho una misma representación «estática» de los saberes y sus peligros.

La consecuencia es que el Libro del caballero et del escudero desarrolla una «educación» doblemente decepcionante para el lector: porque considera, por un lado, que la caballería no es objeto de saber y porque frustra, por el otro, la eventual ansia de conocimientos enciclopédicos de ese mancebo que es, en el fondo, una metáfora del lector. Eso sin duda provocó que los primeros lectores del Libro del caballero et del escudero no encontrasen en él lo que andaban buscando. Si querían caballería se les remitía a otras obras y si querían ciencia se les daba tan solo unas migajas. Eso tal vez explique la mala o poca fortuna textual de las obras juanmanuelinas presuntamente «caballerescas», anteriores al Libro de los estados. Una desapareció y otra se ha conservado en un solo testimonio del que faltan folios y, sobre todo, que fue copiado a partir de una fuente ya muy deturpada a tenor de los espacios en blanco, dejados voluntariamente por el copista. Todo ello nos lleva a pensar que probablemente estas obras no consiguieran llegar a su destinatario ideal pues no supieron darle lo que le apetecía. De ahí, sin duda, que don Juan Manuel quien estaba, como sabemos, muy preocupado por ser leído y admirado, intentara salvarlas; salvarlas del olvido presentándolas luego en el Libro de los estados como excelentes tratados sobre la caballería, sobre todo, precisamente, el Libro del caballero et del escudero que aparece tan excesivamente elogiado por Julio y del que se da además un a modo de completo resumen de los temas tratados. Tal vez era este un último y desesperado conato juanmanuelino por darle a la obra el público que había perdido.

\footnotetext{
${ }^{41}$ Richard P. Kinkade, Los Lucidarios españoles (Madrid: Gredos, 1968), 77.
} 


\section{REFERENCIAS BIBLIOGRÁFICAS}

Alfonso X, Las Siete Partidas, ed. Gregorio López (Salamanca: Andrea de Portonariis, 1555).

Cacho Blecua, Juan Manuel, "Vergüenza, sabiduría y pecado en la literatura medieval castellana (del Bonium a don Juan Manuel)", Principe de Viana. Anejo 18 (2000): 75-102.

Díez Garretas, María Jesús, ed., La obra literaria de Fernando de la Torre (Valladolid: Universidad, 1983).

Kinkade, Richard P., Los Lucidarios españoles (Madrid: Gredos, 1968).

Lawrance, Jeremy, "La autoridad de la letra: un aspecto de la lucha entre humanistas y escolásticos en la Castilla del siglo XV", Atalaya 2 (1991): 85-107.

Llull, Ramon, Llibre de l'orde de cavalleria, en Obres de Ramon Llull [1906], 13 vols. (Palma de Mallorca: Miquel Font, 1986), I.

Lizabe de Savastano, Gladys, "El título XXI de la segunda partida de Alfonso X, patrón medieval del tratado de caballería hispánico", Evolución narrativa e ideológica de la literatura caballeresca, ed. María Eugenia Lacarra (Bilbao: Universidad del País Vasco, 1991).

López de Ayala, Pero,Rimado de palacio, ed. Hugo Bizzarri (Madrid-Barcelona: Real Academia Española-Galaxia Gutenberg- Círculo de Lectores, 2012).

Manuel, don Juan, El libro del caballero et del escudero, en Obras completas, ed. José Manuel Blecua, 2 vols. (Madrid: Gredos, 1981), I.

-, El libro de los estados, ed. Ian R. Macpherson y Robert B. Tate (Madrid: Castalia, 1991).

—, Libro del conde Lucanor, ed. Guillermo Serés (Barcelona: Crítica, 2001).

—, Libro infinido, ed. Carlos Mota (Madrid: Cátedra, 2003).

Maravall, José Antonio, "La idea del saber en una sociedad estática", Cuadernos Hispanoamericanos 197-198 (1966): 324-350.

Rodríguez Velasco, Jesús, El debate sobre la caballería en el siglo XV (Valladolid: Junta de Castilla y León, 1996). 
-, Order and Chivalry. Knighthood and Citizenship in Late Medieval Castile (Filadelfia: University of Pennsylvania Press, 2010).

-, "Invención y consecuencias de la caballería", en Josef Fleckenstein y Thomas Zotz, La caballería y el mundo caballeresco, trad. José Luis Gil Aristu (Madrid: Siglo XXI, 2006), XI-LVIII.

Ruiz, Juan, Libro de buen amor, ed. Jacques Joset (Madrid: Taurus, 1990).

Taylor, Barry, "Los capítulos perdidos del Libro del cavallero et del escudero y el Libro de la caballería", Incipit 4 (1984): 51-69.

Recibido: 4 de febrero de 2021

Aprobado: 9 de marzo de 2021 